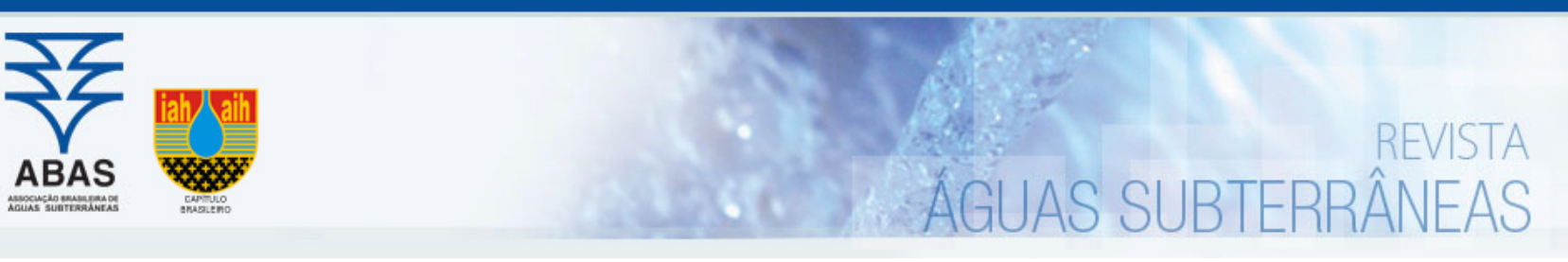

Artigos

\title{
Comportamento hídrico das depressões cársticas da região de Lagoa Santa, MG
}

\section{Karst depressions' hydric behavior of the Lagoa Santa region, MG.}

\author{
Diógenes Guilherme Pampolini Amaral1; Leila Nunes Menegasse Velásquez; Paulo César Horta Rodrigues² \\ 1 Universidade Federal de Minas Gerais (UFMG), Belo Horizonte, MG \\ 2 Centro de Desenvolvimento da Tecnologia Nuclear (CDTN), instituto de pesquisa da Comissão Nacional de Energia Nuclear \\ (CNEN).
}

$\llbracket$ diogenesgeologo@gmail.com, menegase@yahoo.com.br, pchr@cdtn.br

\section{Resumo}

Palavras-chave:

Carste de Lagoa Santa. Depressões Cársticas. Lagoas.

SIG.

Estatística multivariada.

\begin{abstract}
As depressões cársticas se configuram como importantes feições dissolutivas presentes principalmente em regiões calcárias. À luz da típica geomorfologia e hidrogeologia cárstica, este trabalho apresenta as investigações realizadas nas depressões cársticas situadas sobre as rochas pelito carbonáticas do Grupo Bambuí, localizadas nos arredores da Área de Proteção Ambiental (APA) Carste Lagoa Santa (MG). As investigações tiveram como principal objetivo a compreensão do comportamento e desempenho hídrico das 393 depressões cársticas detectadas a partir de Modelo Digital de Elevação (MDE) derivado de uma imagem do satélite ALOS PALSAR. As etapas se constituíram fundamentalmente de geoprocessamento em ambiente SIG, foto observação através de imagens do Google Earth Pro, classificação supervisionada em imagens multiespectrais dos satélites Landsat registradas em quatro períodos hidrológicos distintos (ano com índice pluviométrico normal e ano atipicamente seco). O coeficiente de Kappa e acurácia geral indicaram que as classificações supervisionadas realizadas obtiveram resultados excelentes. As análises estatísticas multivariadas revelaram que a presença de lagoas no interior das depressões cársticas após o período de estiagem em ano hidrológico normal ou em ano de excepcional stress hídrico está relacionada com a morfologia e morfoestrutural. Isto é, as depressões maiores, com grandes profundidades, altos índices de eixos de alongamento e grandes áreas de maciços calcários em seus interiores são aquelas mais favoráveis a possuírem água em seus interiores.
\end{abstract}

Keywords:

Lagoa Santa Karst.

Sink Holes.

Lagoons.

GIS.

Multivariate Statistics.

Revisado por pares.

Recebido em: 15/12/2018.

Aprovado em: 17/04/2019.

\begin{abstract}
The karst depressions are configured as important dissolution features present mainly in limestone regions. From the typical karst hydrogeology and geomorphology's perspective the present study aims to investigate carried out in the karst depressions located on the politic-carbonate rocks of the Bambuí Group, located in the vicinity of Lagoa Santa Karst Environmental Protection Area (APA) - (MG). The investigations had as main objective the understanding of the behavior and water performance of the 393 karst depressions detected from Digital Elevation Model (MDE) derived from an ALOS PALSAR satellite image. The stages consisted basically of geoprocessing via GIS, photo observation through images from Google Earth Pro and supervised classification in multispectral images of the Landsat satellites recorded in four different hydrological periods (year with normal rainfall index and year atypically dry). The Kappa coefficient and Global Accuracy indicated that the supervised classifications performed had excellent results. The multivariate statistical analysis showed that the presence of lagoons in the interior of the karst depressions after drought period in normal hydrological year or in year of exceptional water stress is related to the morphology and morphostructural, that is, to the major depressions with great depths, high indices of stretching axes and large areas of limestone massifs in their interiors are those most favorable to having water in their interiors.
\end{abstract}

\section{INTRODUÇÃO}

Dentre os agentes mais relevantes na modificação da paisagem cárstica, a água se destaca como o de maior influência na gênese e desenvolvimento das feições, associada à composição físico-química da rocha, estrutura rochosa, condições climáticas e tempo (KOHLER, 1989 e FORD e WILLIAMS, 2007;).
Uma depressão cárstica pode ser comparada a uma simples bacia hidrográfica onde ambas possuem semelhanças relevantes, tais como: divisores topográficos, vertentes, talvegues e saídas (confluências, exutórios e/ou sumidouros). O comportamento hídrico de uma bacia hidrográfica é função de suas características morfológicas, ou seja, área, forma, topografia, litologia, pedologia, cobertura vegetal entre outras variáveis (LIMA, 1986; BOM 
DESAN et al., 1992; WHITE, 2007).

Em terrenos com alta frequência de depressões cársticas, o fluxo da precipitação chega a ser quase todo capturado pelas depressões, favorecendo a um intenso fluxo subterrâneo e baixo fluxo superficial.

Devido às peculiares feições dissolutivas que se desenvolvem sobre as rochas calcárias, as técnicas de investigação via sensoriamento remoto (SR) em ambiente de Sistema de Informações Geográficas (SIG) configuram procedimentos amplamente utilizados associados a sofisticadas análises multicritérios e pesquisas multidisciplinares (BOLONGARO-CREVENNA et al., 2005; DE CARVALHO JUNIOR et al., 2014). As depressões se destacam como sendo as feições dissolutivas mais específicas e diagnósticas do cenário cárstico sendo classificadas em três tipos principais: dolinas, uvalas e poljés. Sob o ponto de vista morfodinâmico, elas também desempenham papel hídrico semelhante à de bacias hidrográficas, favorecendo a condução, concentração, armazenamento e recarga de água para o aquífero (BONDESAN et al., 1992; WHITE, 2007; ĆALIĆ, 2011).

Frequentemente as análises morfométricas são desenvolvidas com base em Modelos Digitais de Elevação (MDEs) derivados de imagens de satélites, permitindo investigações mais rápidas e seguras dos alvos. Ademais, os métodos de classificação supervisionada (processo computacional utilizado para identificar informações em uma imagem por meio do mapeamento de pixels que possuem informações semelhantes às de áreas de interesse) vem se tornando cada vez mais úteis para avaliações automáticas sem subjetividade, auxiliando nos processos de interpretações quali-quantitativas da paisagem com acertada confiabilidade (CHEREM, 2008; MENESES e ALMEIDA, 2012; CAMPOS et al., 2016; QUEIROZ et al., 2017).

A extração de atributos morfométricos seguida de cálculos estatísticos elementares e multivariados possibilitam a observação de fenômenos, similaridades e agrupamentos que compõem análises mais detalhadas e, consequentemente, interpretações mais profundas e claras do conjunto dos dados morfométricos (DOS REIS, 1988; OLIVEIRA et al., 2007).

Esse trabalho apresenta o comportamento hídrico das depressões cársticas dentro e nos arredores da APA Carste de Lagoa Santa, baseado na análise de suas características morfoestruturais, morfométricas e de feições residuais (maciços), obtidas por meio de geoprocessamento e estatística. 0 estudo permitiu a classificação das depressões quanto a serem desprovidas de lagoas, ou possuírem lagoas dos tipos intermitente e perene.

\section{CARACTERÍSTICAS DA ÁREA DE ESTUDO}

A área estudada $\left(504,92 \mathrm{~km}^{2}\right)$ dista aproximadamente $30 \mathrm{~km}$ a norte do município de Belo Horizonte, aglutinando parte dos municípios de Confins, Lagoa Santa, Matozinhos, Funilândia, Pedro Leopoldo, Prudente de Morais, Vespasiano, compreendendo a totalidade da APA Carste de Lagoa Santa (Figura 1).

Figura 1 - Localização da área de estudo

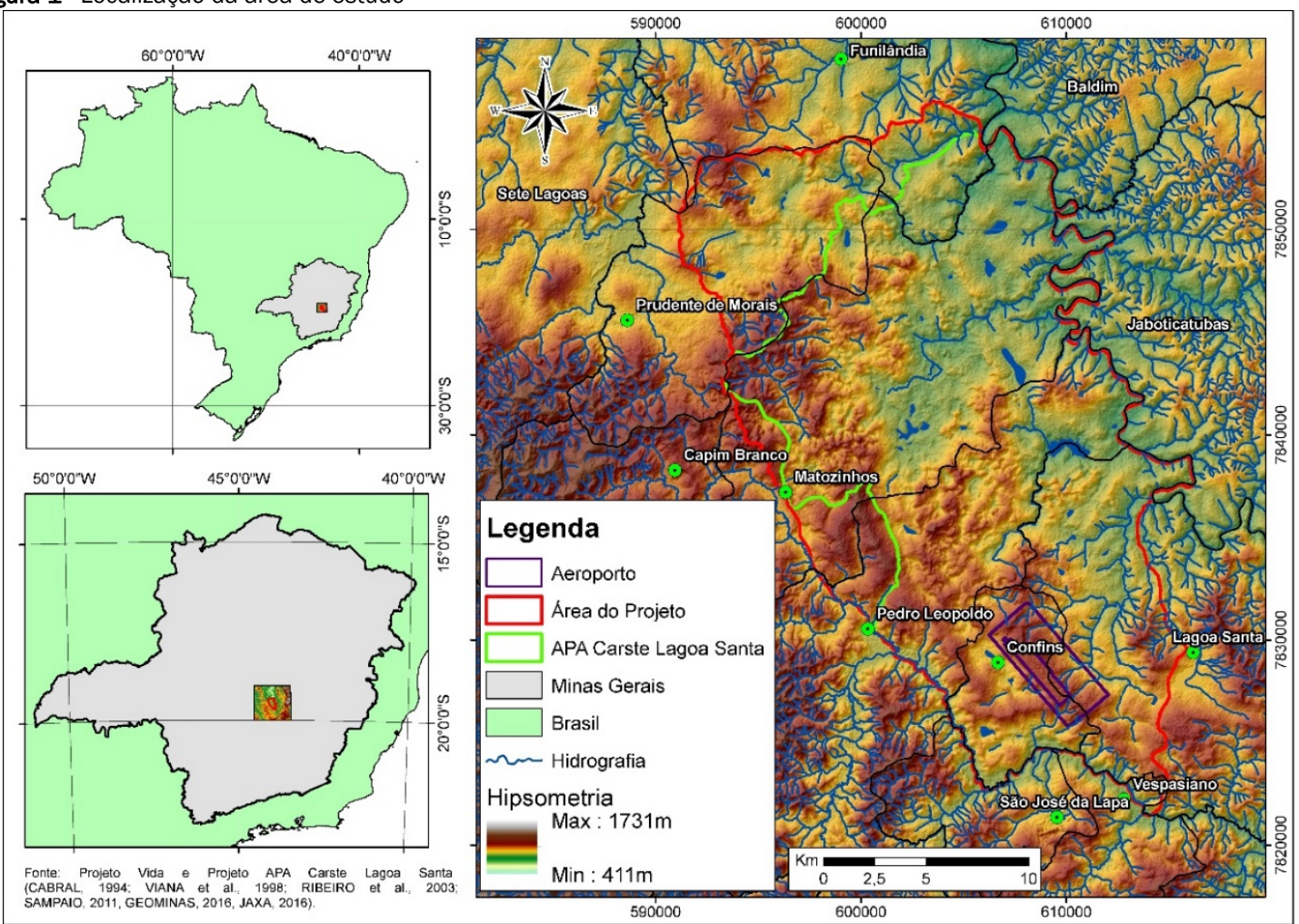

Predominam na área as rochas pelito-carbonáticas das formações basais do Grupo Bambuí, Neoproterozóico, este sobreposto ao embasamento denominado Complexo Cristalino Belo Hori- zonte. 0 embasamento restringe-se a uma estreita faixa a oeste (Figura 2), constituído por rochas gnáissicas graníticas migmatí ticas Arqueanas e Paleoproterozoicas (ALMEIDA e HASUI, 1969 
e RIBEIRO et al., 2003). O Grupo Bambuí é constituído por coberturas sedimentares químicas e clásticas com idade mínima de $630 \mathrm{Ma}$ (DARDENNE, 1978, ALKMIM e MARTINS-NETO, 2001).

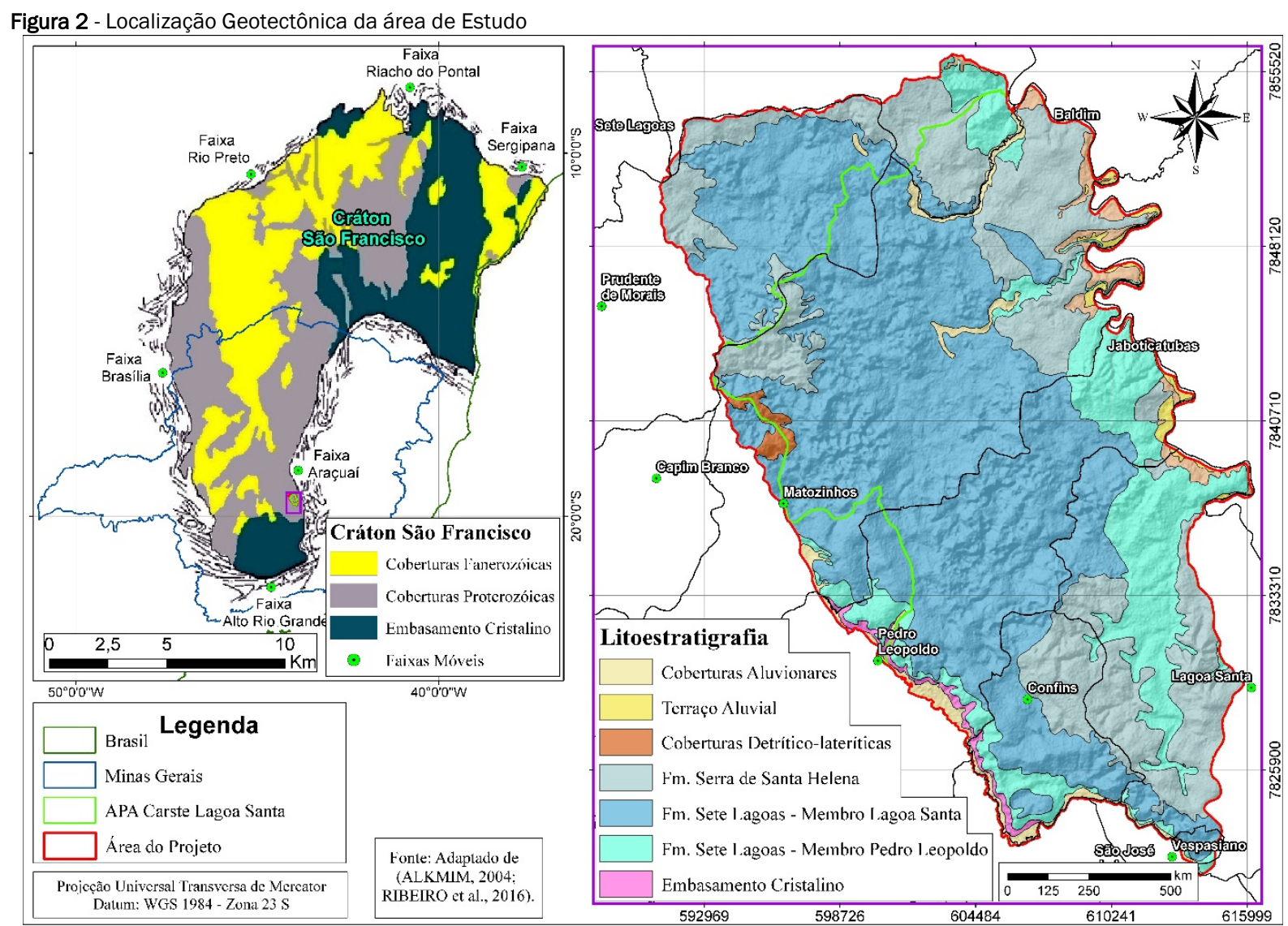

Fonte: Adaptado de Alkmim (2004), Ribeiro et al., (2003) e Ribeiro et al., (2016)

A Formação Sete Lagoas, que na área de estudo manifesta-se na base do Grupo Bambuí, é subdividida nos membros Pedro Leopoldo e Lagoa Santa (DARDENNE, 1978 e VIEIRA, 2007). É a unidade que abriga as típicas feições cársticas (AULER, 1994; BERBERT-BORN et al., 2002; RIBEIRO et al., 2003, VIEIRA et al., 2018).

O Mb. Pedro Leopoldo consiste de uma sequência de calcários impuros, silicosos, com predomínio da fácies de calcissiltitos e calcilutitos finamente laminados com frequentes intercalações argilosas terrígenas delgadas e lentes de calcita e quartzo interdigitadas (VIANA et al., 1998; RIBEIRO et al., 2003 e RIBEIRO et al., 2016). Embora menos carstificado do que o membro superior, em razão da sua impureza, quando sujeito a deformação intensa, apresenta condições locais excelentes para a circulação de água subterrânea.

O Mb. Lagoa Santa sobrepõe-se ao membro inferior, sendo composto por calcarenitos, calcissiltitos e calciruditos puros conferindo às rochas destacada capacidade de dissolução cárstica, configurando o principal aquífero da região.

A Fm. Serra de Santa Helena sobrepõe-se à Fm. Sete Lagoas, constituída de metassiltitos, metargilitos e margas em estratificação plano paralela (DARDENNE, 1978 e RIBEIRO et al., 2003).
Possui baixa potencialidade hidráulica, podendo funcionar como aquitarde, aquiclude ou aquífero pobre.

\section{MATERIAIS E MÉTODOS}

A execução deste trabalho consistiu nas seguintes etapas sequenciais: geoprocessamento com auxílio do software ArcGIS ${ }^{\circledR}$ (ESRI, 2011), SR (foto observação e classificação supervisionada) por meio dos softwares Envi Classic $₫$ e Google Earth $\circledast$ Pro (GOOGLE, 2017), e análise estatística multivariada, utilizando ferramentas do software Minitab® versão 16 (MINITAB, 2006). A base de dados para as análises foi gerada a partir dos seguintes elementos: i) Imagem de radar ALOS (Advanced Land Observing Satellite) PALSAR (Phased Array L-band Synthetic Aperture Radar), resolução $(12,5 \mathrm{~m})$, cena adquirida pela Japan Aerospace Exploration Agency (JAXA, 2016), imagem ALPSRP269566790, de 15/02/2011; ii) Shapefiles e arquivos vetoriais georreferenciados e compilados a partir de mapas e dados do "Projeto VIDA" (CABRAL, 1994; RIBEIRO et al., 2003), "APA Carste de Lagoa Santa" (HERRMANN et al., 1998; VIANA et al.,1998; SAMPAIO, 2011); iii) Série histórica pluviométrica medida na estação de Pedro Leopoldo durante os anos de 1980 a 2016 proveniente da plataforma Hidroweb (ANA, 2017); iv) Imagens LANDSAT 5TM de 27/04/2010 e 18/09/2010 e LANDSAT 8 OLI/TIRS de 06/04/2014 e 29/09/2014, Órbita/Ponto: 
218/73 e 218/74, ambas obtidas no site do Serviço Geológico dos Estados Unidos (USGS, 2017).

A partir do MDE com resolução espacial de $5 \mathrm{~m}$, derivado da imagem ALOS PALSAR geoprocessada, detectaram-se as depressões com profundidade mínima de $3 \mathrm{~m}$, segundo adaptação da metodologia desenvolvida por RODRIGUES (2011).

As depressões detectadas foram foto observadas isto é contrastadas com a imagens RGB do software Google Earth ${ }^{\circledR}$ Pro (GOOGLE, 2017), e aquelas detectadas erroneamente devido a ruídos gerados pela interferência de dosséis vegetais, talvegues de rios, obras de terra, agriculturas com pivôs centrais, foram excluídas. Os maciços calcários foram foto interpretados visualmente nestas imagens RGB.

A fim de validar os métodos empregados na detecção das depressões foram visitadas em campo 73 (18,6\%) depressões aleatoriamente, logrando-se uma confirmação de 100\%. Tal resultado endossou o prosseguimento do trabalho.

Seguiu-se uma classificação supervisionada empregando-se o software Envi Classic ${ }^{\circledR}$ versão 5.0, visando à identificação e detecção dos espelhos d'água presentes no interior das depressões em cenas de quatro períodos hidrológicos de imagens orbitais do satélite Landsat, sendo: 2 imagens Landsat 5TM de um ano com pluviometria normal, 04/2010 e 09/2010, correspondentes ao final do período chuvoso e final da estiagem, respectivamente, e 2 imagens Landsat 8 OLI/TIRS de ano com índice pluviométrico muito abaixo da média histórica da região (04/2014 e 09/2014).

Para a classificação supervisionada foi gerada a composição de bandas espectrais das imagens Landsat visando aumentar os contrastes entre a água e os demais materiais. As composições coloridas adotadas foram a de falsa cor Red-Green-Blue (RGB) para as bandas 5, 4 e 3 nas Landsat 5TM e 6, 5 e 4 para as Landsat 8 OLI/TIRS. As sequências de empilhamento das bandas espectrais foram diferentes entre as Landsat 5TM e Landsat $8 \mathrm{OLI} / \mathrm{TIRS}$ devido aos diferentes intervalos entre os comprimentos de onda dos sensores (MARTINS et al., 2007 e ROSA et al., 2011). Na classificação supervisionada adotou-se o algoritmo da Máxima Verossimilhança, resultando em quatro mapas temáticos digitais da cobertura terrestre com pixels rotulados segundo as áreas de interesse. Para cada imagem classificada foram geradas matrizes de confusão e de erros contendo os dados da Acurácia Geral e o Coeficiente de Kappa da interação, o qual informa se o processamento realizado pode ser legitimado ou não (MENESES e ALMEIDA, 2012; CATTANI et al. 2013), segundo categorização proposta por Landis e Koch (1977) (Quadro 1). Apenas os polígonos da classe Água foram utilizados.

Quadro 1 - Qualidade da classificação e Coeficiente de Kappa.

\begin{tabular}{|c|c|}
\hline Coeficiente de Kappa $(\boldsymbol{K})$ & Qualidade do Raster gerado \\
\hline $0,0-0,2$ & Ruim \\
\hline $0,2-0,4$ & Razoável \\
\hline $0,4-0,6$ & Boa \\
\hline $0,6-0,8$ & Muito boa \\
\hline $0,8-1,0$ & Excelente \\
\hline Fonte: Landis e Koch $(1977)$.
\end{tabular}

Os parâmetros morfométricos, morfoestruturais, de feições morfológicas e hidrológicos das depressões cársticas foram obtidos de acordo com Jennings (1975), Lepsch et al. (1991), Bondesan et al. (1992), Ferrari et al. (1998), Ribeiro et al. (2003), LIMA (1986), Valeriano (2008) e Ćalić (2011), quais foram:

Parâmetros Morfométricos: $)$ Área $\left(\mathrm{m}^{2}\right)$; ii) Perímetro (m); iii) Cota Topográfica do mínimo altimétrico (m); iv) Profundidade $(\mathrm{m})$ : diferença entre a cota topográfica do máximo e o mínimo altimétrico; $\boldsymbol{v}$ ) Índice de Circularidade $(\mathrm{IC})=\frac{12,57 * A}{P^{2}}$ onde: $\mathrm{A}=$ área; $\mathrm{p}=$ perímetro; $v i)$ Declividade Média $(\alpha)$ : ângulo médio de inclinação das vertentes internas.

Parâmetros Morfoestruturais: i)Comprimento dos Eixos de Alongamento $(E A)(m)$ : somatório dos lineamentos no interior das depressões; ii) Índice de Eixos de Alongamento (IE) (m), IE $=\frac{\Sigma E A}{I C}$; iii) Azimute do Eixo Axial (o): relativo ao eixo do alongamento.

Parâmetros de Feições Morfológicas: i) Área de Maciços calcários no interior das depressões $\left[\mathrm{m}^{2}\right]$; ii) Litologia predominante.

Parâmetros Hidrológicos: i) Azimute principal do Espelho d'Água (o); ii) Área de Espelho d'Água em 04/2010 (m²); iii) Área de Espelho d'Água em 09/2010 (m²); iv) Retração de Espelho d'Água entre abril e setembro de $2010\left(\mathrm{~m}^{2}\right)$; v) item anterior em percentagem; vi) Área de Espelho d'Água em abril/2014 (m²); vii) Área de Espelho d'Água em 09/2014 (m²); viii) Retração de Espelho d'Água entre abril e setembro de $2014\left(\mathrm{~m}^{2}\right)$; ix) \% item anterior em percentagem.

O comportamento hídrico das depressões foi analisado a partir de um tratamento estatístico de todos os parâmetros acima, empregando-se a Análise Fatorial (FA) e a Análise de Componentes Principais (PCA). Por meio do critério da raiz latente, na FA, excluíram-se os fatores com autovalores menos influentes na variabilidade dos dados, menores que 1 (HAIR et al., 2005; DE ALENCAR, 2009 e FIGUEIREDO FILHO e SILVA JÚNIOR, 2010). Os fatores que obtiveram cargas fatoriais maiores do que 0,6 seguiram para a PCA, gerando uma nova distribuição por meio do cálculo de matrizes algébricas (MOITA NETO, 2004 e HAIR et al., 2005). Nessa análise identificaram-se os parâmetros com maior significância na variabilidade da distribuição dos dados, bem como a sua influência sobre o comportamento hídrico das depressões a partir da: I) presença ou ausência de lagoas em todas as 393 depressões, nas 46 em 04/2010 e nas 26 em 04/2014; ii) retração total ou parcial das lagoas após o período de estiagem desses anos. 


\section{RESULTADOS E DISCUSSÕES}

\subsection{Identificação e Detecção das Depressões cársticas}

Foram detectadas 564 depressões e excluídas 171 devido a interferências de ruídos no MDE. Pelo mesmo motivo, das 393 resultantes, denominadas depressões cársticas final, 45 (11,5\%) tiveram a forma dos seus polígonos reajustada manualmente (Figura 3). As depressões ocupam 73.264.196m² (14,51\%), todos os maciços calcários $46.189 .738 m^{2}(9,1 \%)$, e apenas os maciços calcários situados no interior das depressões 4.993.766m² (1\%). Juntas, essas feições cársticas de alto potencial para promover a recarga aquífera perfazem 114.425.166m² (22,7\%). Por meio de uma distribuição de frequência com 20 intervalos iguais, do total das 393 depressões cársticas, 350 (89\%) situaram-se no primeiro intervalo com áreas de $2.546 \mathrm{~m}^{2}$ a $306.896 \mathrm{~m}^{2}$ e as restantes 43 (11\%) distribuíram-se nos demais 19 intervalos com áreas de 306.896 $\mathrm{m}^{2}$ a $6.089 .556 \mathrm{~m}^{2}$.

Figura 3 - Mapa resultante da detecção e seleção das depressões cársticas e maciços calcários

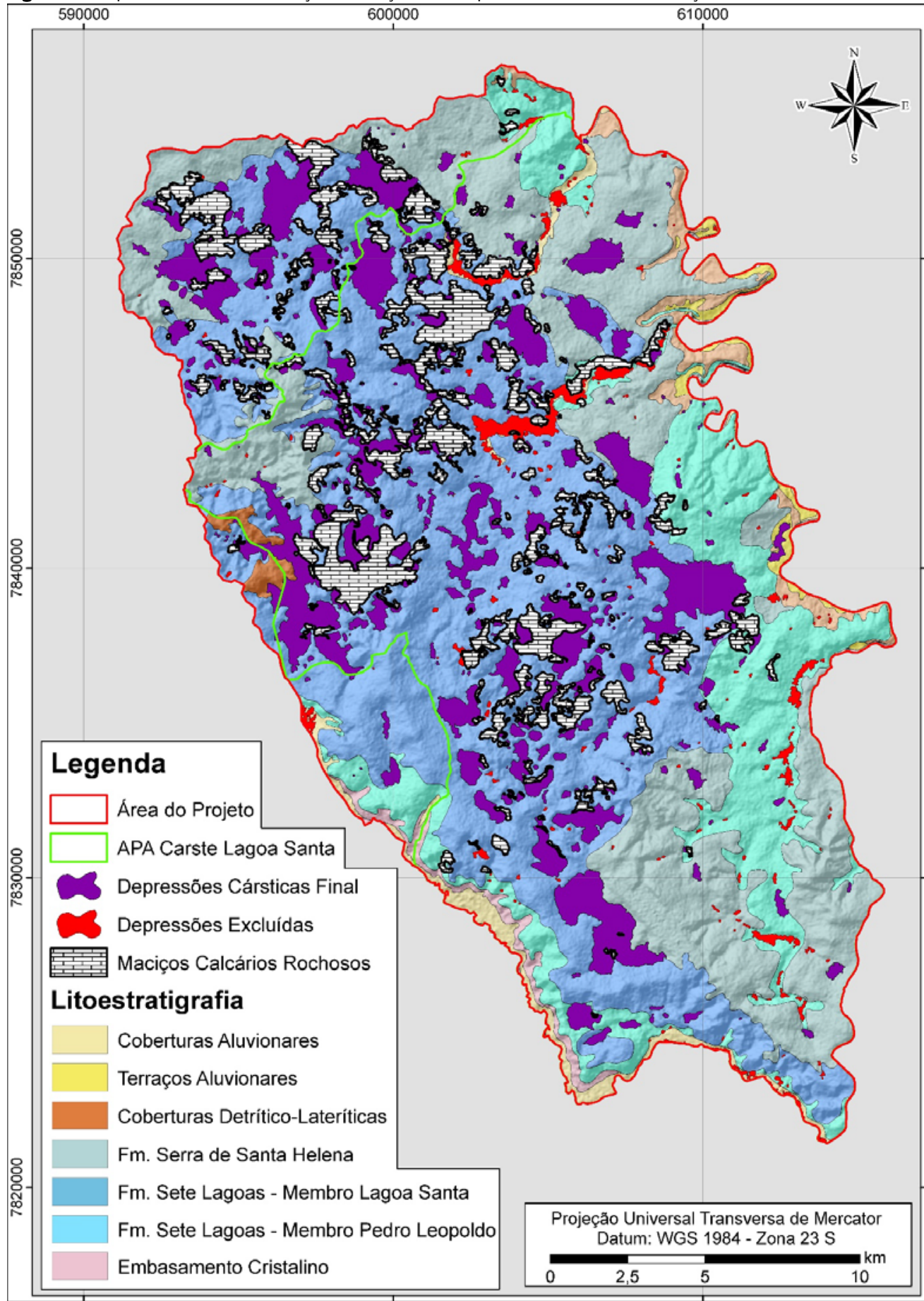




\subsection{Identificação, Detecção e Validação dos Espelhos D'água dentro das Depressões}

Foram definidas cinco classes principais na classificação supervisionada: Água, Vegetação, Solo Exposto, Região Urbana e Cava de Mineração, com aproximadamente 25 áreas de treinamento por classe nas quatro cenas, isto é, para cada classe foram de- finidas ao menos 25 regiões já conhecidas, na imagem a ser classificada, como sendo de uma determinada classe). Os produtos gerados foram quatro imagens Rasters e quatro índices de eficiência indicativos para a validação do procedimento da classificação realizada (Acurácia Global e Coeficiente de Kappa), do que resultou uma qualidade excelente (Tabela 1 ).

Tabela 1 - Índices de qualidade das Classificações Supervisionadas realizadas

\begin{tabular}{lccc}
\hline Cenas & Acurácia Geral & Coeficiente de Kappa & Qualidade da Classificação \\
\hline Abril 2010 & $89,9 \%$ & 0,8549 & Excelente \\
Setembro 2010 & $92,6 \%$ & 0,8941 & Excelente \\
Abril 2014 & $94,2 \%$ & 0,9171 & Excelente \\
Setembro 2014 & $93,9 \%$ & 0,9103 & Excelente \\
\hline
\end{tabular}

Apenas os polígonos da classe Água situados no interior das 393 depressões cársticas já definidas foram utilizados para as investigações posteriores, excluindo-se as demais.

A Figura 4 apresenta os 4 passos executados desde a preparação da imagem Landsat até a seleção dos espelhos d'água no interior das depressões na cena de 04/2010: I) Coloração da imagem Landsat por composição de bandas espectrais; II) Classificação Supervisionada por meio de classes definidas (regiões conhecidas); III) Seleção da classe Água IV) Seleção e validação dos espelhos d'água no interior das depressões. Tal interação foi realizada para as quatro cenas.

\subsection{Comportamento Hídrico das Depressões Cársticas}

Os índices pluviométricos mensais da média histórica e dos anos de 2010 e 2014, utilizados na análise hidrológica das depressões, encontram-se na Tabela 2.

Tabela 2 - Série pluviométrica histórica (mm) da Estação de Pedro Leopoldo (MG)

\begin{tabular}{cccccccccccccc}
\hline Ano & Jan & Fev & Mar & Abr & Mai & Jun & Jul & Ago & Set & Out & Nov & Dez & Média \\
\hline 2010 & 152 & 69 & 179 & 62 & 39 & 3 & 0 & 0 & 23 & 111 & 350 & 367 & 1355 \\
2014 & 54 & 11 & 48 & 58 & 4 & 2 & 53 & 0 & 6 & 75 & 125 & 128 & 564 \\
Média (1980-2015) & 229 & 133 & 156 & 50 & 22 & 8 & 12 & 10 & 42 & 84 & 206 & 294 & 1244 \\
\hline
\end{tabular}

No período de estiagem (abril a setembro) os espelhos d'água tendem a diminuir devido à evaporação e possivel infiltração. E no período chuvoso (outubro a março) os espelhos d'água tendem a aumentar em decorrência da precipitação direta e de possível elevação das cargas hidráulicas dos aquíferos.

Conforme a Tabela 3, no ano de 2010, cujo total pluviométrico de $1.354 \mathrm{~mm}$ está dentro do normal histórico, 46 depressões continham água após o período chuvoso (abril), das quais após o período de estiagem (setembro), 33 mantiveram suas lagoas, porém reduzidas. Já no ano de 2014 , cujo total pluviométrico foi de apenas $564 \mathrm{~mm}$, após o período chuvoso (das 46 depressões com lagoas de abril/2010) somente 26 depressões possuíam água e em setembro, apenas 15 destas mantiveram suas lagoas, porém reduzidas. Assim, individualizaram-se 3 classes de comportamento hídrico das depressões cársticas em: i) Depressão Sempre Seca; ii) Retrai Total (lagoa intermitente) e iii) Retrai Parcial (lagoa perene).

Em 2010 as 33 lagoas perenes tiveram uma retração de 50,4\% da área dos espelhos d'água entre abril e setembro, ao passo que 13 (28,3\%), secaram totalmente. Em abril de 2014 detectaram-se apenas 26 Espelhos d'Água, havendo uma considerável redução, de 43,4\%, do número de lagoas, devido às baixas pluviosidades de 2012 a 2014. Ainda em 2014 as 15 lagoas perenes tiveram uma retração de $42,2 \%$ da área dos espelhos d'água entre abril e setembro, ao passo que 11 (42,3\%) secaram totalmente. 
Figura 4 - Resultado das interações utilizadas na Classificação Supervisionada cena de abril 2010

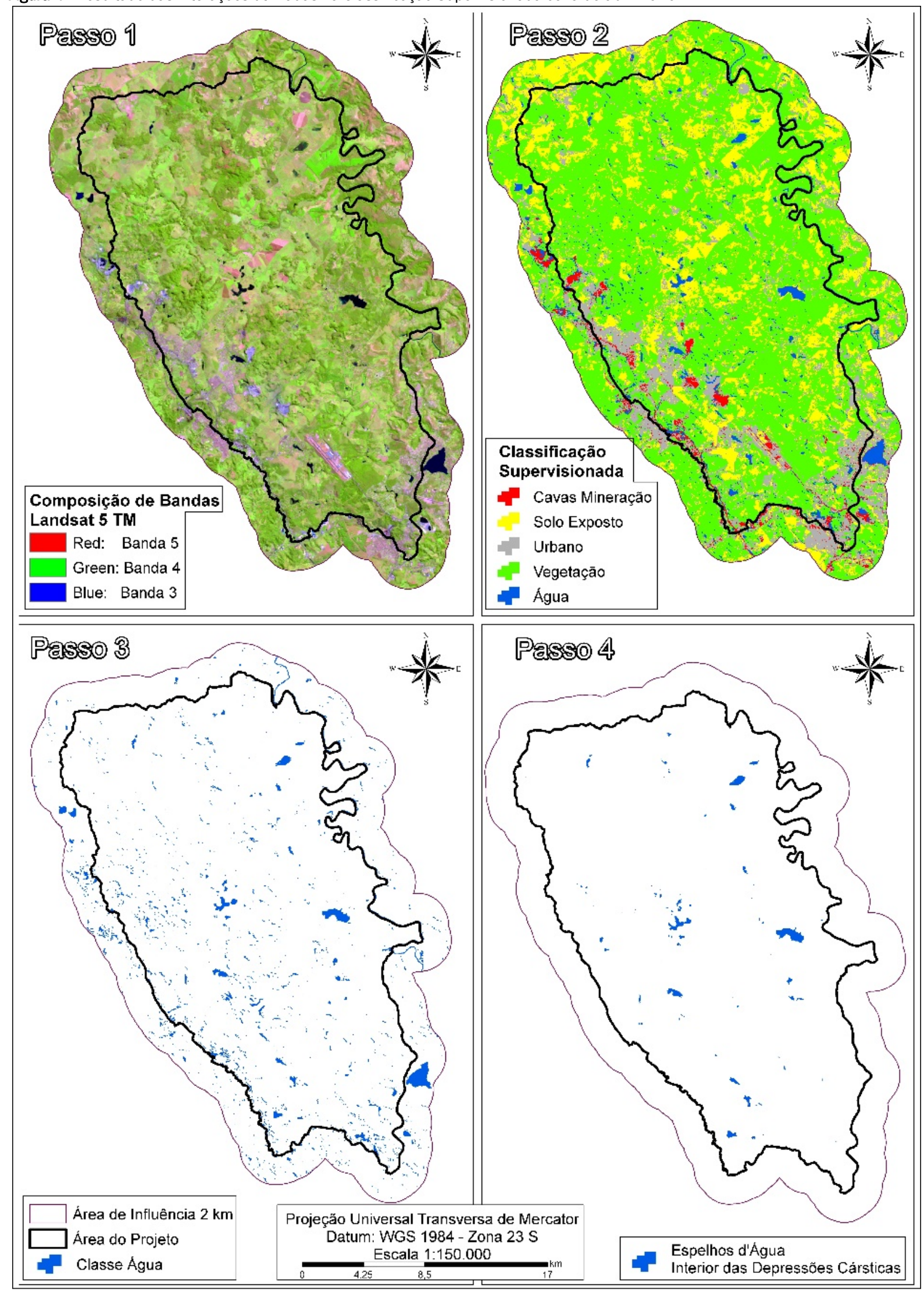


Tabela 3 - Comportamento Hídrico das depressões cársticas via análise dos espelhos d'água

\begin{tabular}{lcccc}
\hline Ano & \multicolumn{2}{c}{2010} & \multicolumn{2}{c}{2014} \\
\hline Total Pluviométrico no ano $(\mathrm{mm})$ & \multicolumn{2}{c}{1354,7} & \multicolumn{2}{c}{564,0} \\
Período hidrológico (mês) & Abril & Setembro & Abril & Setembro \\
Número de Espelhos d'Água & 46 & 33 & 26 & 15 \\
Área Espelho d'Água $\left(\mathrm{km}^{2}\right)$ & 4,3 & 2,2 & 1,0 & 0,6 \\
Retração Espelho d'Água $\left(\mathrm{km}^{2}\right)$ & - & 2,2 & - & 0,4 \\
Porcentagem de Retração & - & $50,4 \%$ & - & $42,2 \%$ \\
Número de Espelhos d'Água que Secaram & - & 13 & - & 11 \\
Porcentagem que Secaram total & - & $28,3 \%$ & - & $42,3 \%$ \\
\hline
\end{tabular}

Para se explorar a influência dos parâmetros morfométricos, morfoestruturais e de feições morfológicas sobre o comportamento hídrico das depressões, foram utilizadas análises estatísticas (FA e PCA) das 393 detectadas, 46 com água em 04/2010 e 26 com água em 04/2014.

Como os parâmetros Área, Perímetro, Comprimento de Eixos de Alongamento e Índice de Eixos (IE) apresentam um mesmo conceito morfocárstico, usaram-se apenas nove parâmetros dentre os doze inicialmente levantados, quais foram: Área, Profundida- de, Cota Topográfica, Declividade Média, Índice de Circularidade (IC), IE, Classe Azimutal do Eixo Axial, Área de Maciços Calcários e Litologia.

\subsubsection{As 393 Depressões Cársticas}

Na PCA, PC1 e PC2 representaram juntos $72,8 \%$ da variância dos dados e os parâmetros de maior peso estão destacados em cada componente (Tabela 4).

Tabela 4 - Matriz de Escores dos parâmetros das 393 depressões cársticas na PCA.

\begin{tabular}{lcc}
\hline Parâmetro & Primeiro Componente & Segundo Componente \\
\hline Área & 0,462 & $-0,092$ \\
Cota Topográfica & $-0,157$ & 0,517 \\
Profundidade & 0,462 & 0,297 \\
Índice de Circularidade (IC) & $-0,339$ & 0,408 \\
Declividade Média & 0,110 & 0,665 \\
Índice de Eixos de Alongamento (IE) & 0,495 & $-0,034$ \\
Área de Maciços & 0,421 & 0,162 \\
Autovalor (Eigenvalue) & 3,413 & 1,678 \\
Variância & 0,488 & 0,240 \\
Variância Acumulada & 0,488 & 0,728 \\
\hline
\end{tabular}

A maior parte das depressões, com ou sem água no período pós chuva (em 04/2010), possuem menores áreas, pequenas profundidades, baixo IE e pequenas áreas de maciços, principalmente aquelas situadas a esquerda do PC1 (Figura 6A).

A presença de água nas depressões após o período chuvoso de 04/2010 está relacionada, majoritariamente, àquelas com fundos em cotas topográficas mais baixas, declividades médias mais suaves e com baixo IC (parte inferior do PC2). Já as depressões com maiores áreas, grandes profundidades, alto IE e grandes área de maciços (fatores esses situados à direita do PC1) são aquelas favoráveis a possuírem lagoas em seus interiores

Ao se classificar as depressões segundo o Tipo Hídrico 2010 (Figura 6B) verificou-se que, a continuidade de água em boa parte das lagoas entre abril e setembro (período de estiagem) se deve a estes mesmos últimos aspectos, à direita do PC1. Esse resultado aponta para a importância dos parâmetros (área, profundidade, IE e área de maciço) para a manutenção de água nas lagoas.

\subsubsection{As 46 Depressões Cársticas com Água em 2010.}

Na PCA, PC1 e PC2 representaram juntos $73,4 \%$ da variância dos dados e os parâmetros de maior peso estão destacados em cada componente (Tabela 5). 
Figura 5 - Gráfico de Escores das 393 depressões cársticas em 2010 na PCA. A). Classificadas quanto a presença de água. B). Classificadas quanto ao Tipo Hídrico: Sempre Seca, Retração Parcial (Perenes), Total (Intermitentes)

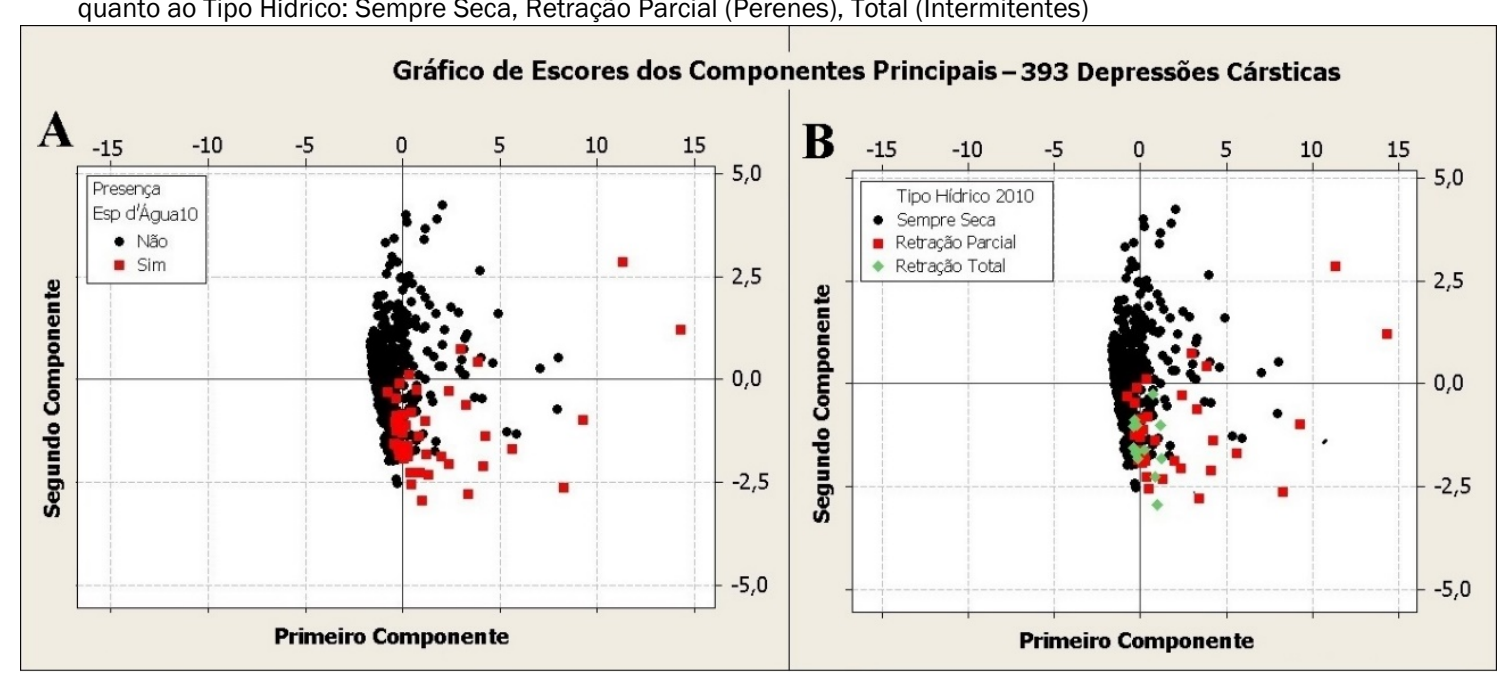

Tabela 5 - Matriz de Escores dos parâmetros das 46 depressões com espelhos d'água em abril 2010 na PCA

\begin{tabular}{lcc}
\hline Parâmetros & Primeiro Componente & Segundo Componente \\
\hline Área & 0,439 & $-0,277$ \\
Cota Topográfica & $-0,003$ & 0,489 \\
Profundidade & 0,498 & 0,151 \\
Índice de Circularidade (IC) & $-0,251$ & 0,596 \\
Declividade Média & 0,324 & 0,540 \\
(IE) & 0,446 & $-0,052$ \\
Área de Maciços & 0,438 & 0,103 \\
Autovalor (Eigenvalue) & 3,710 & 1,426 \\
Variância & 0,530 & 0,204 \\
Variância Acumulada & 0,530 & 0,734 \\
\hline
\end{tabular}

A Figura 7 apresenta o gráfico de escores segundo as cargas fatoriais dos parâmetros das 46 depressões com espelhos d'água em 2010. As lagoas intermitentes são regidas por depressões menores, menos profundas, com menores áreas de maciços e menores IE, à esquerda do PC1.

As lagoas de comportamento perene, embora bem distribuídas numericamente ao longo do PC1, possuem os maiores escores situados à direita, permitindo afirmar que a manutenção de água no interior dessas depressões está vinculada às depressões maiores, com maiores IE, mais profundas e com maiores áreas de maciços em seus interiores e corroboram a análise das 393 depressões.
O PC2 não se mostrou significante para a diferenciação do comportamento hídrico das depressões, ou seja, a Cota Topográfica, Declividade e IC, foram indiferentes à manutenção ou ao esgotamento das lagoas entre abril e setembro de 2010.

\subsubsection{As 26 Depressões Cársticas com Espelhos d’Água em 2014}

Na PCA, PC1 e PC2 representaram juntos $75 \%$ da variância dos dados (Tabela 6) e os parâmetros de maior peso estão destacados em cada componente. 
Figura 6 - Gráfico de Escores das 46 depressões cársticas com espelhos d'água em abril 2010, classificadas segundo o Tipo Hídrico 2010 na PCA.

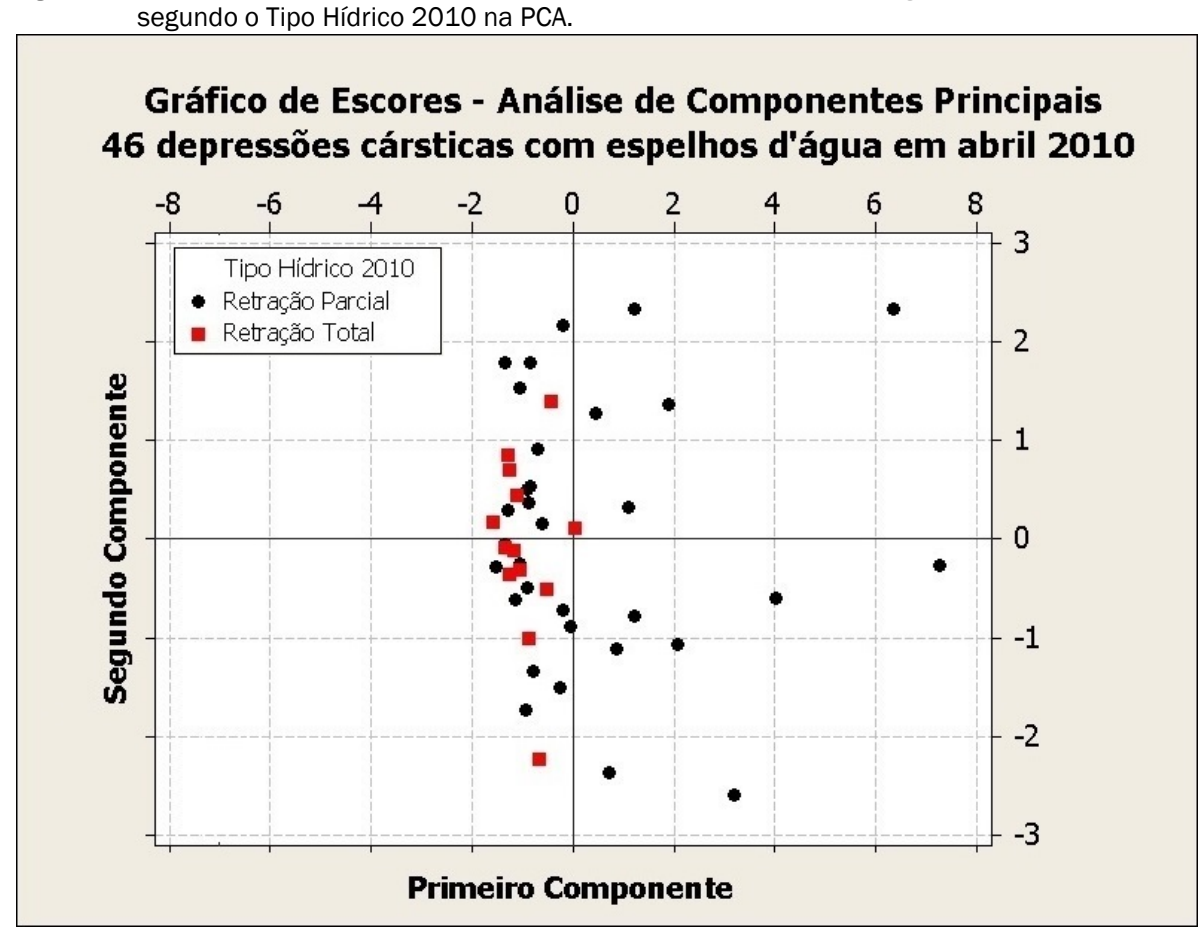

\begin{tabular}{lcc} 
Tabela 6 - Matriz de Escores dos parâmetros das 26 depressões com espelhos d'água em abril 2014 na PCA. \\
\hline Parâmetros & Primeiro Componente & Segundo Componente \\
\hline Área & 0,43 & $-0,29$ \\
Cota Topográfica & 0,05 & 0,52 \\
Profundidade & 0,50 & 0,17 \\
Índice de Circularidade (IC) & $-0,29$ & 0,56 \\
Declividade Média & 0,31 & 0,54 \\
(IE) & 0,44 & $-0,07$ \\
Área de Maciços & 0,45 & 0,09 \\
Autovalor (Eigenvalue) & 3,65 & 1,60 \\
Variância & 0,52 & 0,23 \\
Variância Acumulada & 0,52 & 0,75 \\
\hline
\end{tabular}

A Figura 8 apresenta o gráfico de escores conforme as cargas fatoriais dos parâmetros das 26 depressões com espelhos d'água em 04/2014. Pouco menos da metade das lagoas perenes tenderam a ocorrer principalmente em depressões maiores, mais profundas, com maior IE e de maior área de maciços (maiores escores à direita do PC1), confirmando a permanência e relevância desses fatores na manutenção das lagoas, especialmente em ano de severa crise hídrica, como no presente caso.

Contrariamente, a distribuição das lagoas intermitentes tendeu a se concentrar principalmente nas depressões menores, menos profundas, baixo IE, e com menor área de maciços, à es- querda do PC1. E, diferentemente de 2010, aquelas situadas em topografias mais baixas, menor IC e declividades suaves (fatores inferiores do PC2) foram aquelas favoráveis à exaustão total das lagoas. O resultado é bastante significativo, pois corrobora tais fatores, embora sejam importantes para a formação das lagoas em ano pluviométrico normal (2010), não são eficientes para a manutenção das mesmas, chegando a influenciar no esgotamento das lagoas ao final da estiagem em ano atipicamente seco, 09/2014, e a se comportarem de modo indiferente face à perenidade ou intermitência das lagoas ao final da estação seca de 2010. 
Figura 7 - Gráfico de Escores das 26 depressões cársticas com espelhos d'água em abril 2014, classificadas segundo o Tipo Hídrico 2014 na PCA

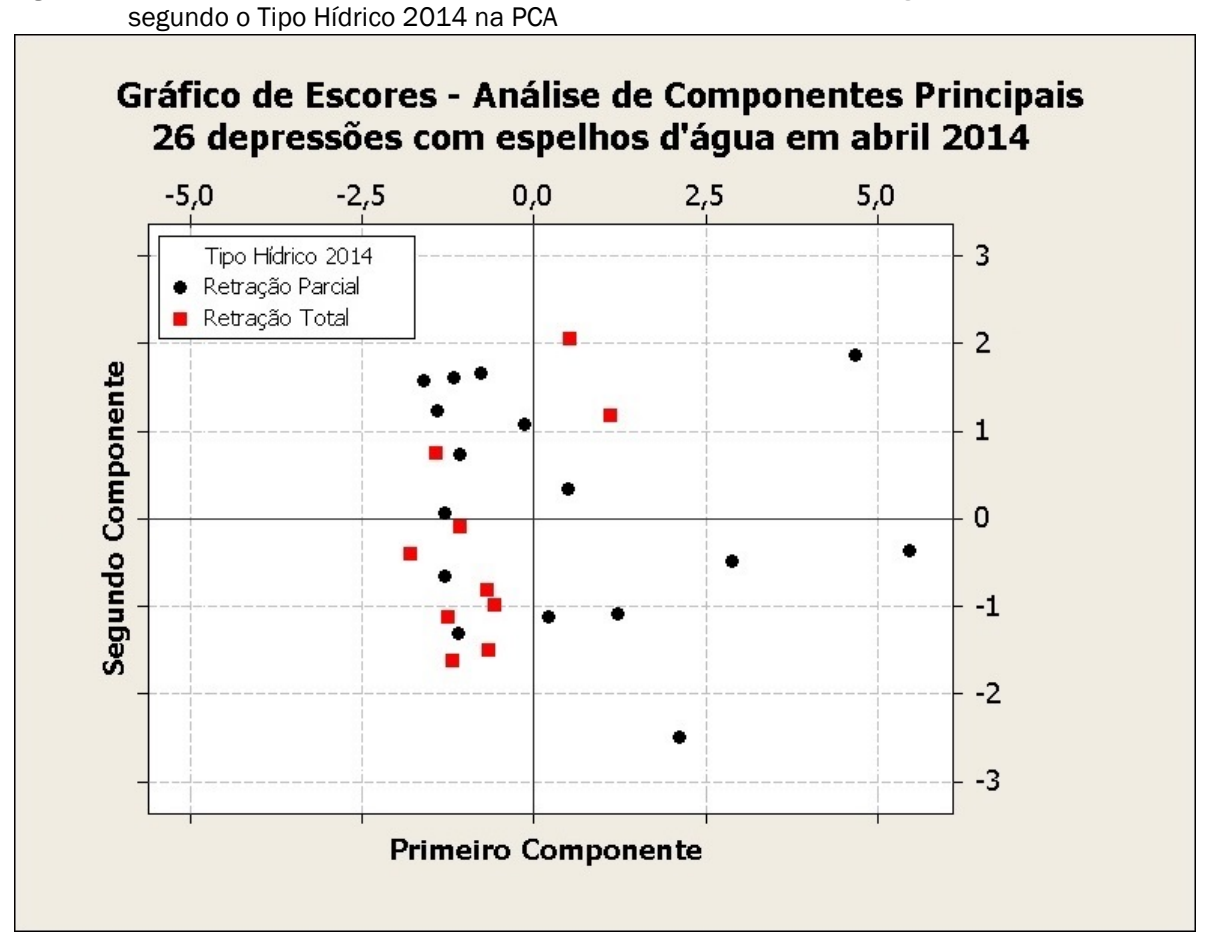

\section{DISCUSSÃO}

As depressões cársticas favoráveis ao acúmulo de água após a estação chuvosa em ano pluviométrico normal (2010) ou atipicamente seco (2014) foram: aquelas situadas em menores cotas topográficas, com declividade mais suaves e com formas mais irregulares. Entretanto, esses fatores não se mostraram eficientes para determinar a permanência da água ao final da estiagem.

Já os parâmetros que se mostraram favoráveis tanto ao acúmulo de água como à sua manutenção até o final da estiagem foram mais diversificados, dentre morfométricos (maiores área e profundidade), morfoestrutural (maior IE) e de feição morfológica (maior área de maciços calcários), que foram determinantes nos anos normal e seco. Essas depressões são ao mesmo tempo maiores e mais profundas, sob os seguintes coeficientes de correlação: Área x IE (0,94), Área x Profundidade $(0,79)$, Área x Área de Maciços $(0,50)$, Profundidade x IE $(0,80)$, Profundidade $x$ Área de Maciços $(0,65)$, IE x Área de Maciços $(0,52)$.

O desempenho hídrico das depressões deve ser avaliado à luz dos resultados logrados quanto ao potencial de atuarem como feições que favorecem a infiltração e recarga aquífera ou como pontos de equilíbrio das cargas hidráulicas dos aquíferos livres ou confinados. Dentre as depressões propícias à recarga estariam as que se mostraram sempre secas e as que se esgotam totalmente ao final da estiagem (Retrai Total) Figura 8. 


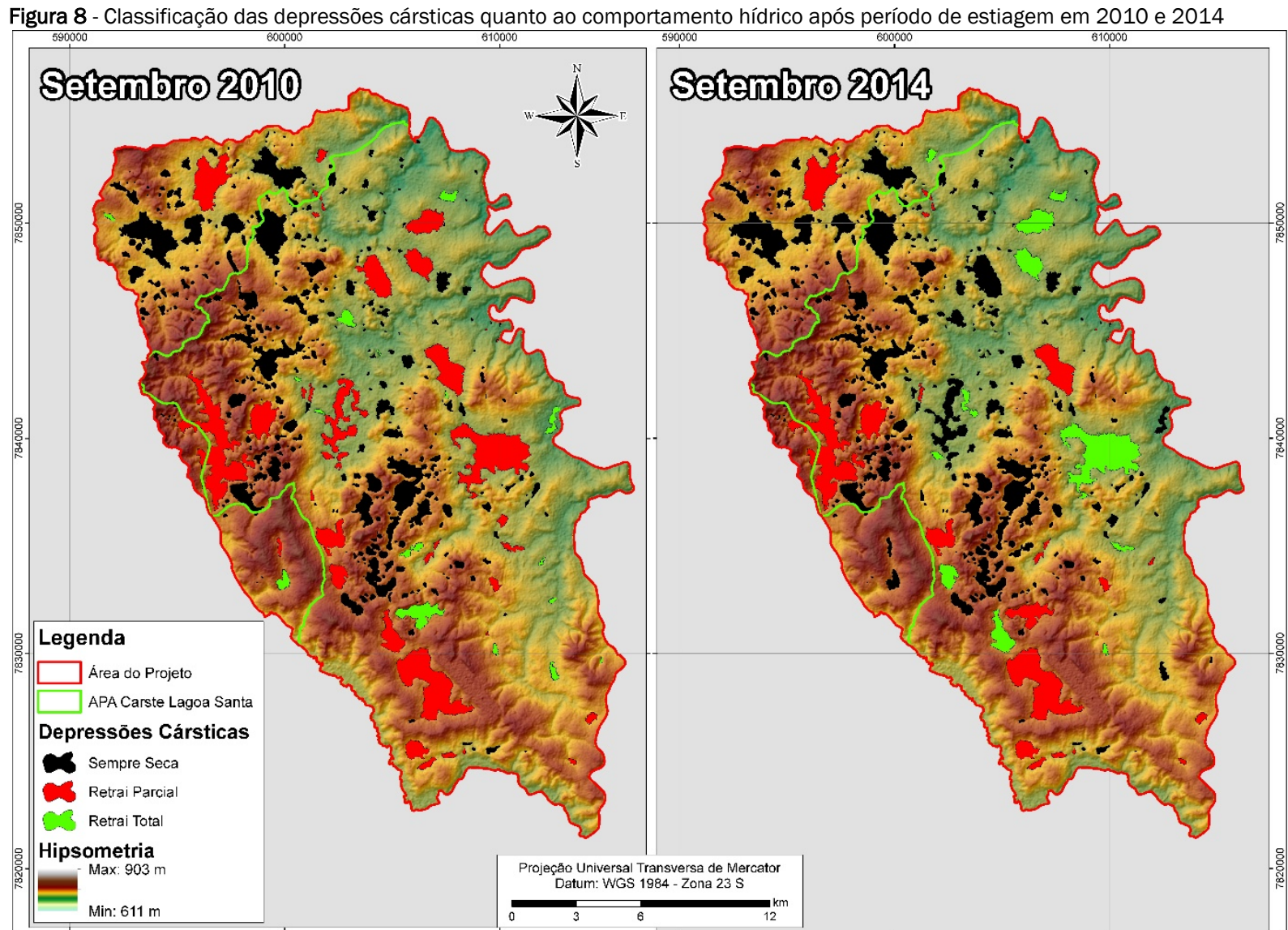

Os valores mais elevados do fator morfoestrutural (IE) relacionado à manutenção da água ao final da estiagem aponta para uma alimentação ascendente por aquíferos, assim como o fator feição morfológica aponta para uma alimentação descendente através dos maciços calcários. Tais depressões são ao mesmo tempo maiores e mais profundas.

Outrossim, das 46 depressões com água em ano pluviométrico normal, 04/2010, 16 (35\%) mantiveram suas águas até o final da estiagem do último ano de um período de 3 anos de stress hídrico (09/2014). Estas são as depressões que seguramente estão conectadas ao aquífero e/ou são dependentes da recarga dos maciços em seu interior.

\section{CONCLUSÃO}

As imagens ALOS PALSAR foram consideradas adequadas para a geração de um MDE com boa resolução e, consequentemente, a identificação de feições dissolutivas. A utilização de SR aliado à técnica de geoprocessamento se mostrou relevante para a assertividade e eficiência do método de detecção e seleção das depressões cársticas, confirmado via investigação em campo. A utilização da classificação supervisionada se mostrou como uma técnica eficiente para o estudo hídrico das depressões cársticas, apresentando resultados sem subjetividade, mais seguros, com potencialidade para realizar processamentos excelentes com alta acurácia e elevado índice de Kappa.
As análises das depressões cársticas em ano hidrológico normal (2010) e atipicamente seco (2014) apresentaram comportamento hídrico semelhante quanto aos fatores determinantes, tanto para a presença, quanto para a manutenção de lagos no seu interior.

Pode-se considerar que depressões sempre secas e as que se esgotam totalmente ao final da estiagem, em especial no ano hidrológico normal, são as de elevado potencial para promovem a recarga aquífera.

Esses resultados se mostram relevantes para a gestão do uso do solo e recursos hídricos, considerando o elevado número de depressões cársticas que tipificam essa região, a função ecológica das lagoas e a considerável dependência da água subterrânea.

\section{REFERÊNCIAS}

AGÊNCIA NACIONAL DE ÁGUAS (ANA). HidroWeb: sistemas de informações hidrológicas. Disponivel em: www.snirh.gov.br/hidroweb/publico/medicoes_historicas_abas.jsf. Acesso em: 31 out. 2017.

ALKMIM, F. F.; MARTINS-NETO, M. A. A bacia intracratônica do São Francisco: Arcabouço estrutural e cenários evolutivos. In: PINTO, C. P.; MARTINS-NETO, M. A. Bacia do São Francisco: Geologia e Recursos Naturais. SBG, Belo Horizonte. p. 9-30, 2001. 
ALKMIM, F. F. O que faz de um cráton um cráton? O Cráton do São Francisco e as Revelações Almeidianas ao Delimitá-lo, p. 1735. In: MANTESSO-NETO, V.; BARTORELLI, A.; CARNEIRO, C. D. R. e BRITO-NEVES, B. B. (ORG.). Geologia do continente sul-americano: evolução da obra de Fernando Flávio Marques de Almeida, 647p. Editora Beca, São Paulo, 2004.

ALMEIDA, F. F. M. de; HASUI, Y. Geocronologia do centro-oeste brasileiro. Rev. Mineração e Metalurgia, Rio de Janeiro, n. 50, p. 43-46, 1969.

AULER, A. Hydrogeological and hydrochemical characterization of the Matozinhos - Pedro Leopoldo Karst, Brazil. Bowling Green: Faculty of the Department of Geography and Geology / Western Kentucky. 1994. 110p. (Thesis, Master of Science)

BERBERT-BORN, M. L. Carste de Lagoa Santa, MG - Berço da paleontologia e da espeleologia brasileira. In: SCHOBBENHAUS, C.; CAMPOS, D. A.; QUEIROZ, E. T.; WINGE, M.; BERBERT-BORN, M. L. C. (Eds.). Sítios geológicos e paleontológicos do Brasil. 1. ed. Brasília: DNPM/CPRM - Comissão Brasileira de Sítios Geológicos e Paleobiológicos (SIGEP), v. 01. 415-430, 2002.

BOLONGARO-CREVENNA, A.; TORRES-RODRIGUEZ, V.; SORANI, V.; FRAME, D.; ARTURO ORTIZ, M. Geomorphometric analysis for characterizing landforms in Morelos State, Mexico. Geomorphology, 67, 407-422, 2005.

BONDESAN, A., MENEGHEL, M., SAURO, U. Morphometric Analysis of Dolines. International Journal of Speleology, 21, n.1-4, p. 1-55, 1992.

CABRAL, J. A. L. Projeto VIDA - Viabilidade Industrial e Defesa Ambiental. Região de Sete Lagoas - Lagoa Santa: Informações Básicas para a Gestão Territorial. (Série Ordenamento territorial v.3). Cartografia geotécnica de planejamento. Belo Horizonte: CPRM/CETEC, 1994.

ĆALIĆ, J. Karstic uvala revisited: Toward a redefinition of the term. Geomorphology, 134 p. 32-42, 2011.

CAMPOS, W. W.; GASPAR, J.; LAGE, M. O.; KAWASHIMA, R. S.; GIANNOTTI, M.; QUINTANILHA, J. A. Avaliação de classificadores de imagem de satélite a partir do uso de uma técnica de votação. RBC. Revista Brasileira de Cartografia (ONLINE), v. 68, p. 16531664, 2016.

CATTANI, C. E. V.; MERCANTE, E.; SOUZA, C. H.; WRUBLACK, S. C. 2013. Desempenho de Algoritmos de Classificação Supervisionada para Imagens dos Satélites RapidEye. In: SIMPÓSIO BRASILEIRO DE SENSORIAMENTO REMOTO - SBSR, 16., 2013.Anais... Foz do Iguaçu, 2013.

CHEREM, L. F. S. Análise morfométrica da Bacia do Alto do Rio das Velhas - MG. Dissertação (mestrado) - Universidade Federal de Minas Gerais, Instituto de Geociências, 2008.110 f.

DARDENNE, M. A. Síntese sobre a Estratigrafia do Grupo Bambuí no Brasil Central. In: Congresso Brasileiro de Geologia, 30, Recife, 1878. Anais.... Recife, SBG, n. 2, p.597-610, 1978.
DE ALENCAR, B. J de. A. Análise multivariada no tratamento da informação espacial uma abordagem matemático-computacional em análise de agrupamentos e análise de componentes principais. Tese (Doutorado em Tratamento da Informação Espacial) - Pontifícia Universidade Católica de Minas Gerais. Minas Gerais, 2009.

DE CARVALHO, O. A.; GUIMARÃES, R. F.; MONTGOMERY, D. R.; GILLESPIE, A. R.; TRANCOSO R. A. T. G.; MARTINS, E. S.; SILVA, N. C. Karst Depression Detection Using ASTER, ALOS/PRISM and SRTM-Derived Digital Elevation Models in the Bambui Group, Brazil. Remote Sensing, v. 6. p. 330-351, 2014.

DOS REIS. S. F. Morfometria e Estatística Multivariada em Biologia Evolutiva. Revista Brasileira de Zoologia, v. 5, n.4, p. 571580, 1988.

ESRI. ArcGIS Desktop: Release 10. Redlands, CA: Environmental Systems Research Institute, 2011.

FERRARI, J. A.; HIRUMA, S. T.; KARMANN, I. Caracterização morfométrica de uma superfície cárstica do Vale do Ribeira, São Paulo (Núcleo Caboclos - Petar). Revista do Instituto Geológico, v. 19, n.1, 1998.

FERREIRA, C. W. S.; LIMA. C. DE S.; CAVALCANTI, L. C. DE S.; SANTOS, A. H. DE O. Caracterização Morfométrica da Bacia Hidrográfica do Açude Cachoeira II, no Município de Serra Talhada-PE, Brasil. In: SEMINÁRIO LATINO-AMERICANO E II SEMINÁRIO IBERO-AMERICANO DE GEOGRAFIA FÍSICA, 6., 2010, Coimbra. Anais... Sustentabilidade da 'Gaia'; Ambiente, Ordenamento e Desenvolvimento. Coimbra, p. 26, 2010.

FIGUEIREDO FILHO, D. B.; SILVA JÚNIOR, J. A. Visão além do alcance: uma introdução à análise fatorial: opinião pública (UNICAMP. Impresso), v. 16, p. 160-185, 2010.

FORD, D. C.; WILLIAMS, P. W. Karst Geomorphology and Hydrology. 2. ed. John Wiley \& Sons, Chichester, Reino Unido, 2007. $562 \mathrm{p}$.

GOOGLE. Programa Google Earth Pro. Imagem das imediações da APA Carste Lagoa Santa - MG. Acesso em: 15 maio 2017.

HAIR Jr., J. F.; BLACK, W. C.; BABIN, B. J.; ANDERSON, R. E.; TATHAM, R. L. Análise Multivariada de Dados. 6.ed. Porto Alegre, Bookman, 2005.

HERRMANN, G.; KOHLER, H. C.; DUARTE, J. C.; CARVALHO, P. G. S. (Org.) APA Carste de Lagoa Santa - Gestão Ambiental. IBAMA/CPRM, Belo Horizonte, 1998. 57p.

JAXA - Japan Aerospace Exploration Agency. ALOS. Disponível em: Http://www.jaxa.jp/projects/sat/alos/index_e.html. Acesso em: 15 nov. 2016.

JENNINGS, J. N. Doline morphometry as a morphogenetic tool: New Zealand examples. New Zealand Geographer, 1975. 31p.

KOHLER, H. C. 1989.Geomorfologia cárstica na região de Lagoa Santa. Tese (Doutorado) - Universidade de São Paulo. 113p. 
LANDIS, J. R.; KOCH, G. G. The measurement of observer agreement for categorical data. Biometrics, v. 33, n. 1, 1977.

LEPSCH, I. F., BELINAZZI JR., R., BERTOLINI, D., ESPINDOLA, C. R. Manual para levantamento utilitário do meio físico e classificação de terras no sistema de capacidade de uso. Campinas: SBCC, 1991.

LIMA, W. P. Princípios de Hidrologia florestal para o manejo de bacias hidrográficas. Piracicaba; ESALQ/USP, 1986. 282p.

MARTINS, E. S. P. R.; MENESCAL, R. de A.; SCHEREN-WARREN, M.; CARVALHO, M. S. B. de S.; MELO, M. S.; PERINI, D.S; OLIVEIRA, F. de A. J. 2007. Utilização de Imagens CBERS para Mapeamento dos Espelhos D'água do Brasil. In: SIMPÓSIO BRASILEIRO DE SENSORIAMENTO REMOTO, INPE. 13., 2007. Anais... Florianópolis, Brasil, 2007.

MENESES, P. R.; ALMEIDA, T. Introdução ao processamento de imagens de sensoriamento remoto. Universidade de Brasília: Brasília, 2012.

MINITAB Inc. Statistical software data analysis software. Versão 16, 2006.

MOITA NETO, J. M. Estatística multivariada - uma visão didáticametodológica crítica. Revista de Filosofia e Ensino, v. 1, n.1, p. 1-1, 2004.

OLIVEIRA, S. N de.; CARVALHO JÚNIOR, O. A de.; SILVA, T. M da.; GOMES, R. A. T.; MARTINS, E. de S.; GUIMARÃES, R. F.; SILVA, N. $C$ da. Delimitação automática de bacias de drenagens e análise multivariada de atributos morfométricos usando modelo digital de elevação hidrologicamente corrigido. Revista Brasileira de Geomorfologia, v. 8, p. 3-21, 2007.

QUEIROZ, T. B.; SOUZA, R. S.; BALDIN, T.; BATISTA, F. J.; MARCHESAN, J.; PEDRALI, L. D.; PEREIRA, R. S. Avaliação do Desempenho da Classificação do Uso e Cobertura da Terra a Partir de Imagens Landsat 8 e Rapideye na Região Central do Rio Grande do Sul. Geociências (UNESP. Impresso), v. 36, p. 569-578, 2017.

RIBEIRO, J. H.; TULLER, M. P.; FILHO, A. D.; PADILHA, A V.; CÓRDOBA, C. V. Projeto VIDA: mapeamento geológico, região de Sete Lagoas, Pedro Leopoldo, Matozinhos, Lagoa Santa, Vespasiano, Capim Branco, Prudente de Morais, Confins e Funilândia, Minas Gerais - relatório final, escala 1:50.000, $2^{\mathrm{a}}$ ed.; Belo Horizonte: CPRM, 2003. 54p., Mapas e anexos (Série Programa Informações Básicas para Gestão Territorial - GATE, versão digital e convenção)

RIBEIRO, C. G.; MEIRELES, C. G.; LOPES, N. H. B.; ARCOS, R. E. C. Levantamento geológico estrutural aplicado aos fluxos dos aquíferos cárstico-fissurais da região da APA Carste de Lagoa Santa,
Minas Gerais. Trabalho de Graduação (Geologia) - Instituto de Geociências, Universidade Federal de Minas Gerais, Belo Horizonte, 2016. 157p.

RODRIGUES, P. C. H. Detecção semiautomática de depressões altimétricas por geoprocessamento a partir de Sensoriamento Remoto (dados SRTM) - Potencialidades para detecção de dolinas (cársticas ou não). Publicação interna CDTN - 910. - Belo Horizonte: CNEN/ CDTN, 2011.

ROSA, L.; ALVES, M. de C.; SANCHES, L. Uso de composições de bandas do satélite Landsat 5 TM para caracterizar a dinâmica da variação de áreas alagadas no Pantanal mato-grossense. In: SIMPÓSIO BRASILEIRO DE SENSORIAMENTO REMOTO - SBSR, 15., 2011. Anais... Curitiba, PR, Brasil, INPE, 2011.

SAMPAIO, J. L. D. Inventário digital da APA (Área de Proteção Ambiental) Carste Lagoa Santa e algumas implicações. Tese (Doutorado) - Pontifícia Universidade Católica de Minas Gerais, Programa de Pós-Graduação em Tratamento da Informação Espacial. Belo Horizonte, 2010,

USGS - UNITED STATES GEOLOGICAL SURVEY. Landsat data continuity mission. U.S. Department of the Interior, U.S. Geological Survey. 2012-3066. Disponível em: <https://earthexplorer.usgs.gov/>. Acesso em: 15 nov. 2017.

VALERIANO, M. M. Topodata: guia para utilização de dados geomorfológicos locais. São José dos Campos, SP: Coordenação de Ensino, Documentação e Programas Especiais. INPE (Boletim), 2008.

VIANA, H. S.; KOHLER, H. C.; TAVARES, V. P. Síntese da Geologia, Recursos Minerais e Geomorfologia In: VIANA, H. S.; KOHLER, H. C.; TAVARES, V. P. (Org.) APA Carste de Lagoa Santa - meio físico. Volume I. Belo Horizonte IBAMA/CPRM, 1998.

VIEIRA, L. C. A Formação Sete Lagoas (Grupo Bambuí) e as variações paleoambientais no final do Proterozóico. Tese (Doutorado) - Instituto de Astronomia, Geofísica e Ciências Atmosféricas, Universidade de São Paulo, São Paulo, 2007. 190 p. 120.

VIEIRA, L. C. M.; DUSSIN, T. M.; VELÁSQUEZ, L. N. M. Geoquímica e condições paleoambientais de deposição das rochas carbonáticas da formação Sete Lagoas na região da área de proteção ambiental Carste de Lagoa Santa, MG. Geochimica Brasiliensis, v.32, n.1, p.1-19, 2018.

WHITE, W. B. Groundwater flow in karstic aquifers. In: J. W. Delleur., editor. The Handbook of Groundwater Engineering. v. 21. CRC Press, Taylor and Francis Group, 2007. 47p. 